\title{
Content Analysis of Hospital Reviews From Differing Sources: Does Review Source Matter?
}

Sayeedul Islam, PhD

Farmingdale State University of New York, Farmingdale, New York, United States

(iD) https://orcid.org/0000-0002-9678-2742

Sara Mir, DDS

Farmingdale State University of New York, Farmingdale, New York, United States

Caroline Defina, BA

Farmingdale State University of New York, Farmingdale, New York, United States

Carolina Silva, BA

University of Central Florida, Orlando, Florida, United States

Contact: islams@farmingdale.edu

\section{Abstract}

Social media has had an impact on how patients find and evaluate medical professionals and their experiences of modern healthcare. Qualitative research in healthcare has increased its focus on social media. The present study examined 497 reviews of hospitals in the Pittsburgh area across three websites: Google, Yelp, and Healthgrades. Using computerized content analysis tools (CATA), we analyzed positive and negative comments to identify key themes. Key themes and words included "doctor," "hospital," "staff," and "time." These findings highlight the importance of medical staff to patient experience. Results indicated that Yelp had the lowest average rating. CATA also revealed that the central term for Google reviews was "hospital," for Healthgrades reviews it was "doctor," and the central term for Yelp reviews was "patient." These central terms reflect the focus of each website. The present study highlights the importance of healthcare professionals understanding the source of reviews and being cautious about how social media comments are used in decision-making about the practice. Future research should try to expand this approach to other cities and countries to evaluate cross-cultural effects on social media comments.

Keywords: Healthcare; Qualitative analysis; Social media; Patient reviews; Patient experience

Date Submitted: December 22, 2020 | Date Published: February 11, 2021

\section{Recommended Citation}

Islam, S., Mir, S., Defina, C., \& Silva, C. (2021). Content analysis of hospital reviews from differing sources: Does review source matter? Journal of Excellence in Nursing and Healthcare Practice, 3, 1-22. https://doi.org/10.5590/JSWGC.2021.3.1.01 


\section{Introduction}

Recent research has shown that the business of healthcare has been affected in a variety of ways by social media content (Hilliard, 2012; Islam et al., 2016; Ranney \& Genes, 2016). Social media has had a profound effect on how patients find and share information about their healthcare experiences (Morahan-Martin, 2004; Terry, 2009), as well as how healthcare providers respond to these concerns. First, patient satisfaction has grown in importance due to the Affordable Care Act (ACA) requirements around satisfaction ratings (Atinga et al., 2011). Second, patients can now find data on doctors and hospitals from a variety of sources that may affect their choice of healthcare provider (Hawn, 2009). As information access increases, patients can make a broader range of choices around their healthcare. These sources of data are not always under the control of healthcare organizations. Online health information can provide increased opportunities for healthcare organizations to communicate with patients as well as a way for patients to communicate their healthcare experiences (Gravili, 2013). Patients increasingly use online reviews to make decisions about which healthcare providers to visit (Greaves \& Millett 2012). Trends in other industries, such as finance (Devries, 2012) and hospitality (Chetta et al., 2017), indicate that social media comments affect consumer choices, and it behooves the healthcare industry to understand how sources affect ratings. The present study explores different social media sites, the ratings provided, and the qualitative data associated with these ratings.

\section{Background}

Healthcare research has increased its use of qualitative methods to better understand the patient experience (Sarasohn-Kahn, (2008); Smailhodzic et al., 2016). Qualitative research allows healthcare researchers and practitioners to understand the experience of patients (Smith et al., 2003), healthcare workers (BradburyJones et al., 2014), and administrators (Schultz et al., 2011). Qualitative methods have been shown to be effective in understanding and improving processes within healthcare systems (Pope et al., 2002).

Much research has been conducted using interviews and coding schemes to understand these experiences (Chenail, 2011). This research has often generated new data from interviews and focus groups. However, social media represents a rich data source for qualitative researchers in healthcare that does not require data collection and may provide more open descriptions. Social media are defined as "online platforms for interactions to occur around various health topics relating to patient education, health promotion, public relations, and crisis communication" (Househ et al., 2013). Social media tools include blogs, microblogging (i.e., Twitter), social networking (i.e., Facebook), and video- and file-sharing sites (i.e., YouTube). Social media data has been used in a variety of studies to better understand healthcare processes and procedures. Hospitals have shown a marked increase in the use of social media platforms to communicate with patients (Griffis et al., 2014). Chan \& Chen (2019) conducted a study on the effect of pregnancy apps on healthcare outcomes and showed the impact of this technology on women's pregnancy experiences. Laranjo et al. (2015) reviewed the effect of social media sites on patient behavioral change over time and found that social media support could maintain patient behaviorial change. Williams et al. (2014) conducted a meta-analysis on the effect of social media interventions on exercise and diet. These studies of social media focused on quantitative research and indicated the overall impact that the communication tool could have on health outcomes.

Studies of social media's impact on healthcare have noted the interplay between patients, organizations, and service providers (Auriemmo et al., 2018; Househ, 2013). As a crowdsourced, user-produced form of text, social media data allows researchers unique understanding of the communication processes between organizations, healthcare workers, and patients. Most qualitative research in this area has focused on patient experience and health-related outcomes, with the research centered around understanding the patient experience. These experiences are understood to be communicated through social media and can have an impact on organizations' and medical practitioners' financial bottom line (Apenteng, 2020). 


\section{Literature Review}

Social media research in healthcare has focused primarily on website reviews with some focus on social media platforms (Hawn, 2009; Hamm et al., 2013; McCaughey et al., 2014) and an occasional focus on how to best utilize these platforms to maximize value for healthcare organizations or sole practitioners (Grajales et al., 2014). Most of the research uses the individual physician as the lens of analysis. Physicians are often reviewed on websites that are available to laypeople (Ventola, 2014). Physicians must be mindful of these sites and reviews as they can drive patient choices about care and potentially impact the financial wellbeing of a physician's practice. Antheunis et al. (2013) found that physicians primarily used LinkedIn and Twitter for marketing and networking, while patients used Twitter and Facebook for knowledge and advice. Patients are making healthcare choices and those physicians that wish to continue to grow their practices must be mindful of online reviews. Social media presents an opportunity to engage in consistent evaluation of healthcare providers' service, patient reactions, and organizational effectiveness (Cordoş et al., 2017).

Donnally et al. (2018) conducted a comprehensive review of the ratings of spinal surgeons across three healthrelated websites (i.e., Healthgrades) and found that surgeons with a social media presence received higher numbers of comments on their review pages. They reviewed the comments for health-related information but did not look at what language drove positive and negative reviews.

Nwachukwu et al. (2016) reviewed the ratings of surgeons across three different review websites (Healthgrades, Vitals, and Rate MDs) and found that female surgeons were more likely to receive higher ratings and that social media presence also lead to higher ratings. The comments were analyzed for primarily health-related information related to patient experience, but no significant differences were found between the ratings websites.

Korzadeh (2018) reviewed ratings across publicly available websites (i.e., Google) and hospital-provided ratings. This study found that the ratings provided by the hospital were higher than those available on Google, signaling that organizations know the value of higher ratings in driving financial performance.

McLellan (2019) extended the ratings research further by focusing on comments and data from a variety of medical sources as well as Google ratings. Google had significantly more ratings than the health-oriented sites, indicating its importance as a source of healthcare-related information for consumers. Google also included more comments, but these comments were not content analyzed.

Baksh and Mesfin (2014) conducted a content analysis of eight different health-related websites. A researcher content analyzed and coded the comments. The analyses revealed that scheduling and time with the patient were primary factors in the higher ratings. While this analysis provided a cross-sectional view across a variety of websites (i.e., Google, Healthgrades, WebMD), the language that drove positive and negative ratings was not identified.

Across these studies, two themes emerge. First, most of these studies focus on physician-specific ratings rather than ratings of the hospital facility or organization. Unlike other service providers, where the organization is the focal point, the review process in these studies focused on individual providers (i.e., physicians). This is despite the impact of other players such as nurses and administrators on patient care within the larger healthcare system. Second, much of the research has included comments but has converted written comments into quantitative variables (i.e., number of comments included) rather than reviewing the substance of what patients had written regarding their care. This leaves a significant gap in the research literature that the present study hopes to address. 


\section{Theoretical Framework}

Healthcare researchers have begun to utilize qualitative analyses; however, many have yet to fully realize the value of computer-assisted textual analysis (CATA) (Abualigah et al., 2020). To address the calls for increased use of qualitative methods (Cohen \& Crabtree, 2008), many researchers have used traditional content coding (Roth \& Whitehead, 2019). Traditional content coding includes the application of the Weber Protocol involving a human coder who categorizes and analyzes text for themes and meaning (Duriau et al., 2007). CATA is defined as "a research technique involving the essential use of computer software for making replicable and valid inferences from text to their context” (Tian \& Stewart, 2005). The CATA approach can make the process of content analysis much faster by using established dictionaries to evaluate language. Technological tools that are used in CATA can conduct sentiment analysis and language aggregation.

Sentiment analysis is concerned with assessing text for emotions, often positive and negative emotions. Healthcare researchers (Georgiou et al., 2015) have evaluated sentiment analysis tools for their efficacy and validated several established tools. Research has indicated that the open-source tools provide more effective sentiment analysis than commercial ones. The present study will use several open-source tools (i.e., Voyant Tools) in its analyses. Abirami \& Askarunisa (2017) recommend the use of multiple data sources to better understand the sentiment of any given subject.

To conduct an effective sentiment analysis, researchers must use dictionaries to tag words as either positive, negative, or neutral (Young \& Soroka, 2012). Sentiment analysis dictionaries such as the Lexicoder dictionary have been used in a variety of settings (www.lexicoder.com). The Lexicoder dictionary has most commonly been used to evaluate news articles' sentiment and political content (Soroka et al., 2015). This dictionary has also been used to analyze sentiment and perceptions of healthcare treatments (Sabel \& Dal Cin, 2016). A key criticism of CATA is that the method utilizes machines to understand human language. However, we propose approaching CATA in healthcare through the lens presented by Todres et al. (2009), who proposed a humanist framework through which to view qualitative research. This framework addressed some limitations presented by Bradley (2005) by focusing on the individual human experience that a CATA tool would allow researchers to identify. In other words, CATA does not replace human coders but allows humans to process larger groups of data with an eye towards standardized analysis.

One concern regarding qualitative methods is the lack of replicability and credibility of the results. Miyata and Kai (2009) highlight four epistemological axes that can be used to evaluate qualitative and quantitative research. They conclude that qualitative and quantitative research methods need not be in competition with one another. CATA allows qualitative researchers to take unstructured text and use a dictionary to apply quantitative methods. In addition to applying a numerical framework to the text, CATA can also be used to extract text using frequency categories to better understand the language used. This addresses one of the prime uses of qualitative data in evidence-based healthcare, that of a thematic tool to identify issues for change and improvement (Popay \& Williams, 1998; Al-Busaidi, 2008). CATA also addresses some of the concerns of Pope et al., 2000), who stated that qualitative research must be done with an eye towards categorization due to human subjectivity. CATA shifts the need away from training the human to perceive the text correctly to choosing the correct dictionary and extraction tools to identify sentiment and language.

Prior studies that have used CATA techniques have looked at large-scale databases from a single source (Greaves et al., 2013). A variety of studies have used multiple databases but have not compared comments between these sites. Research has also evaluated comments using the unit of analysis of the individual provider (i.e., physician), yet few studies have looked at the hospital as the unit of analysis. The present study builds upon previous work by Islam et al. (2016). 
Lagu et al. (2017) also showed that the characteristics of the websites used impacted physician reviews with factors such as punctuality and question structure impacting the quantitative and qualitative ratings. Despite identifying the impact, little information from the qualitative comments on these sites was used to evaluate patient experience and physician reviews.

Figure 1 shows the updated qualitative patient experience model from Islam et al. (2016)'s paper on urgent care centers. The authors of the present study updated the model presented in Figure 1. The model posits that patients experience staff interactions, care delivery, and the facility during their healthcare experiences. These experiences are filtered through patient perceptions. Patients then choose a social media or review site that impacts their written comments and ratings on external review websites. The researchers propose using a grounded theory and phenomenological approach to understand the process.

Figure 1: Qualitative Patient Experience Model

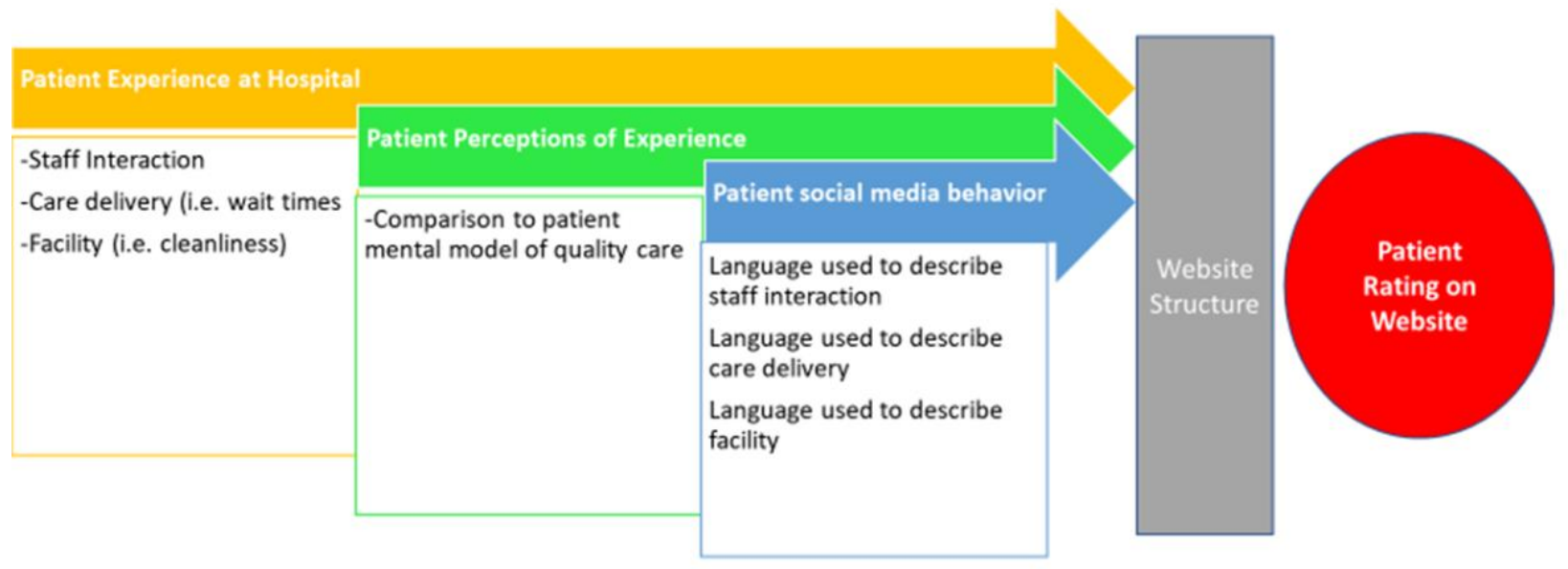

\section{Research Questions}

Research Question 1: Are there differences in quantitative ratings of hospitals between review sites?

Research Question 2: What are the differences in language used on different review sites to describe patient experiences within hospitals?

\section{Method}

The present study examines ratings and language used in reviews of hospitals in the Pittsburgh area, following a similar methodology to Black et al. (2009) and Islam et al. (2016). The study uses a content analysis approach to understand open-source comments on public websites. Morris (1994) defines content analysis as "a qualitative research technique that uses a set of procedures to classify or categorize communications to permit valid inferences to be drawn." Computerized content analysis is considered qualitative because qualitative research attempts to develop "an understanding of the meaning and experience dimensions of humans' lives and social worlds" (Fossey et al., 2002). Computerized content analysis uses computers to assist 
in processing and assigning meaning to vast amounts of text (Morris, 1994). The study was reviewed and approved by the IRB.

Pittsburgh was chosen as a location because it was a city with multiple hospitals with a variety of specialties that would provide a wide range of potential responses. Specifying a location from which to collect the data allowed researchers to control for other factors that might affect data from multiple cities and locations, based on recommendations from Black et al. (2009). Area hospitals from Pittsburgh, Pennsylvania, were chosen, and a researcher collected 497 comments about 10 different Pittsburgh area hospitals and healthcare providers from three sources, Yelp, Google, and Healthgrades. Healthgrades was chosen because it is a site dedicated to health ratings and bills itself as "the leading online resource for comprehensive information about physicians and hospitals." (Hilliard, 2012). Google was chosen because it is viewed as the leader in online searches (Thelwell, 2008) and a source of much patient information. Yelp describes itself as connecting people with great local businesses. Yelp was chosen because it has traditionally been viewed as a site that impacts consumer choices and has been little studied in the healthcare space (Hicks et al., 2012). Researchers gathered 214 comments from Google, 263 from Healthgrades, and 20 from Yelp. Comments and ratings were collected between January 1, 2019, and October 31, 2019.

Ratings were analyzed using a one-way ANOVA with the website (Google, Yelp, Healthgrades) as the independent variable and the rating as the dependent variable. Post hoc analyses were done using Tukey's test. Computerized content analysis tools were used to text mine the comments from Google, Healthgrades, and Yelp. RIOT scan was used to analyze the sentiment of each set of comments using the Lexicoder dictionary (Daku et al., 2015). The Lexicoder dictionary consists of 4,567 positive and negative words and phrases. It has also been validated against manually coded data and has outperformed other valence dictionaries (Soroka et al., 2015). The sentiment analysis scores represent the overall positive and negative sentiment. RIOT scan calculates this score by taking the number of positive words and subtracting the negated positive sentiment and adding back in the negated negative sentiment. To calculate negative sentiment, the number of negative sentiment words is subtracted from the number of negated negative sentiment and added to the negated positive sentiment. In other words, only the positive or negative sentiment remains through this calculation. The Lexicoder dictionary defines which terms are positive, negative, and in which context the words negate positive or negative sentiment. The corpus was organized according to positive and negative ratings and by rating source (Google, Healthgrades, and Yelp). Comments were categorized as negative if the rating received was 1 or 2 , and high ratings were defined as 3 , 4 , and 5 . After the data was organized in this way, the Lexicoder dictionary was used to analyze the rating of positive and negative affect.

The researchers used another text analytic tool known as Voyant Tools, which is "a web-based reading and analysis environment for digital texts" (voyant-tools.org). Using Voyant Tools, the researchers conducted another computerized content analysis of the comments across the different platforms. Voyant tools produced the most popular words by corpus and word clouds of the most popular terms. Voyant tools also identified distinctive language by corpus. Distinctive language is defined as words used primarily in one text versus the others.

The corpus was also analyzed using Tropes (semantic-knowledge.com). Tropes is a natural language processing (NLP) and semantic classification software that allows researchers to extract text and identify the style of the language used in the reviews. Tropes was also used to identify the top word pairs in each segment of the corpus as well as the text style. Using Tropes, the researchers then organized these data into star diagrams. Star diagrams show relations between words and word categories. The star diagram indicates a central term and the words that come before and after that central term. This diagram allows the researcher to understand the language that comprises the central concepts in the corpus. 


\section{Results}

Table 1 contains average rating by website. Average ratings for service were lowest on Yelp $(M=2.06)$ and highest for Healthgrades $(M=4.13)$.

Table 1: Mean Numerical Rating by Rating Source

\begin{tabular}{lrrr}
\hline \multicolumn{1}{c}{ Rating Source (Google, Yelp, Healthgrades) } & Mean & \multicolumn{1}{c}{ SD } & \multicolumn{1}{c}{ N } \\
\hline Google & 3.371 & 1.880 & 210 \\
Healthgrades & 4.137 & 1.612 & 263 \\
Yelp & 2.056 & 1.697 & 18 \\
\hline
\end{tabular}

Table 2 shows the results of the ANOVA analysis. There was a significant effect of review source on quantitative ratings $F=20.098, d f=2, p<.05$ for the three conditions.

Table 2: Numerical Rating by Rating Source

\begin{tabular}{|c|c|c|c|c|c|}
\hline Cases & Sum of Squares & df & Mean Square & $\mathbf{F}$ & $\mathbf{p}$ \\
\hline Rating Source (Google, Yelp, Healthgrades) & 121.004 & 2.000 & 60.502 & 20.098 & $<.001$ \\
\hline Residual & 1469.045 & 488.000 & 3.010 & & \\
\hline
\end{tabular}

Note: Type III Sum of Squares

Table 3 contains results of post-hoc analyses by rating source. Post-hoc analyses revealed that Google ratings were lower than Healthgrades, with Yelp the lowest of all.

Table 3: Post Hoc Comparisons-Rating Source (Google, Yelp, Healthgrades)

\begin{tabular}{llccccc} 
& & Mean Difference & SE & t & Cohen's d & p tukey \\
\hline Google & Healthgrades & -0.765 & 0.161 & -4.767 & -0.441 & $<.001$ \\
& Yelp & 1.316 & 0.426 & 3.088 & 0.705 & 0.006 \\
Healthgrades & Yelp & 2.081 & 0.423 & 4.924 & 1.287 & $<.001$ \\
\hline
\end{tabular}

Note: Cohen's $d$ does not correct for multiple comparisons.

Table 4 contains overall sentiment analysis scores. The results in Table 4 indicate that Yelp had the most negative language used and Healthgrades had the most positive language used. A computerized content analysis was conducted using RIOT scan (Boyd, 2013) and the Lexicoder dictionary (Young \& Soroka, 2012) to assess each sources' sentiment. Yelp had the lowest level of positive sentiment $(M=2.35)$ and Healthgrades had the highest positive sentiment $(M=6.76)$. These results seem to indicate that Healthgrades draws in more reviews related to positivity and may be used by those reviewers who have the most experience and knowledge of healthcare. Yelp reviews seem to be more general and focused on service. Time seems to be a concern across all platforms and seems to drive ratings of quality across hospital systems.

Table 4: Overall Corpus Positive-Negative Affect Lexicoder Sentiment Dictionary

\begin{tabular}{lllll}
\hline & Average Sentence Length & Sentences & Negative Affect & Positive Affect \\
\hline Google & 12.86 & 692 & 3.05 & 6.67 \\
Healthgrades & 10.22 & 942 & 2.83 & 6.76 \\
Yelp & 13.35 & 81 & 4.35 & 2.31 \\
\hline
\end{tabular}


Table 5 contains sentiment analysis results by review source and positive and negative rating. Google had the highest positive sentiment rating while Yelp's negative ratings had the highest amount of negative sentiment.

Table 5: Positive-Negative Affect by Source and Rating

\begin{tabular}{llllll}
\hline & & $\begin{array}{l}\text { Average Sentence } \\
\text { Length }\end{array}$ & Sentences & $\begin{array}{l}\text { Negative } \\
\text { Affect }\end{array}$ & $\begin{array}{l}\text { Positive } \\
\text { Affect }\end{array}$ \\
\hline Google & Positive Rating & 12.65 & 375 & 1.33 & 10.26 \\
& Negative Rating & 13.06 & 318 & 5.03 & 2.57 \\
Healthgrades & Positive Rating & 4.34 & 718 & 1.76 & 8.63 \\
& Negative Rating & 4.13 & 224 & 5.42 & 2.27 \\
Yelp & Positive Rating & 4.34 & 57 & 2.37 & 4.41 \\
& Negative Rating & 4.5 & 24 & 5.11 & 1.53 \\
\hline
\end{tabular}

Figures 2, 3, 4, and 5 contain word clouds of the Google, Healthgrades, and Yelp comments. The most frequent words across the corpus of text (Google, Yelp, and Healthgrades) were "doctor," "staff," "hospital," and "time." The longest comments were left with the Healthgrades site, followed by Google and Yelp. Vocabulary density or the amount of higher-level vocabulary used in the corpus was also calculated. Yelp reviews had the highest vocabulary density (.418).

Note. For Figures $2-5$, the larger the text the more often the word appears in the corpus.

Figure 2: Google Comments Word Cloud

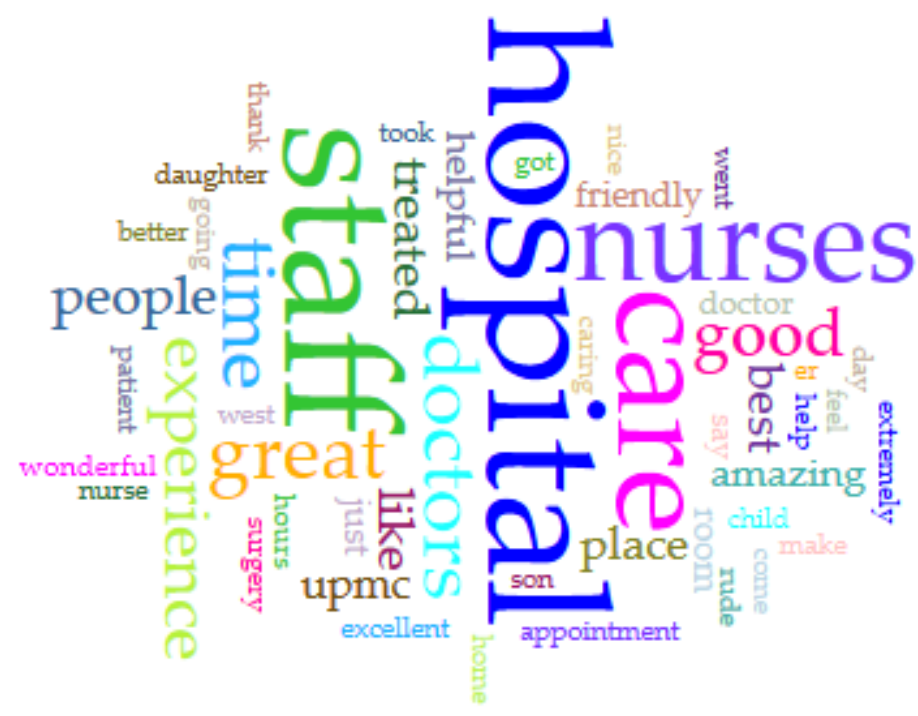


Figure 3: Healthgrades Word Cloud

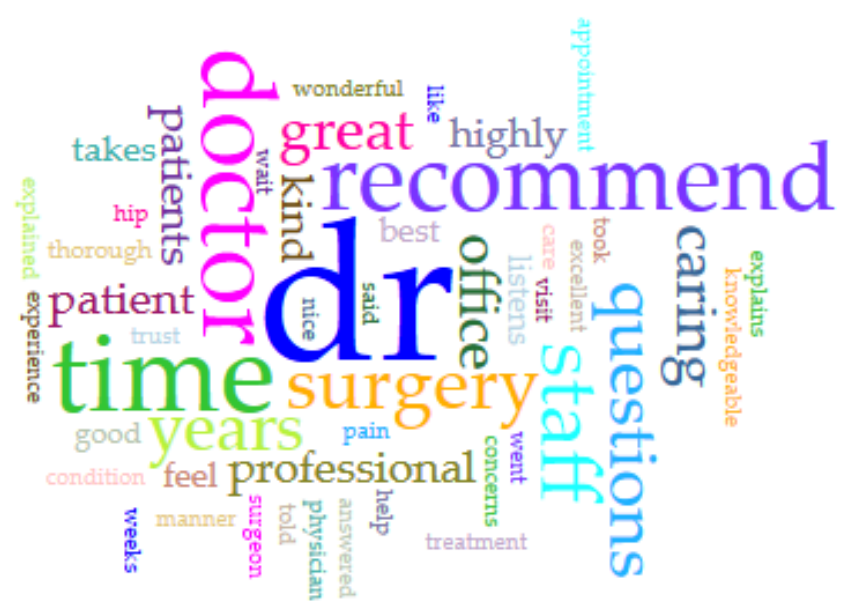

Figure 4: Yelp Word Cloud

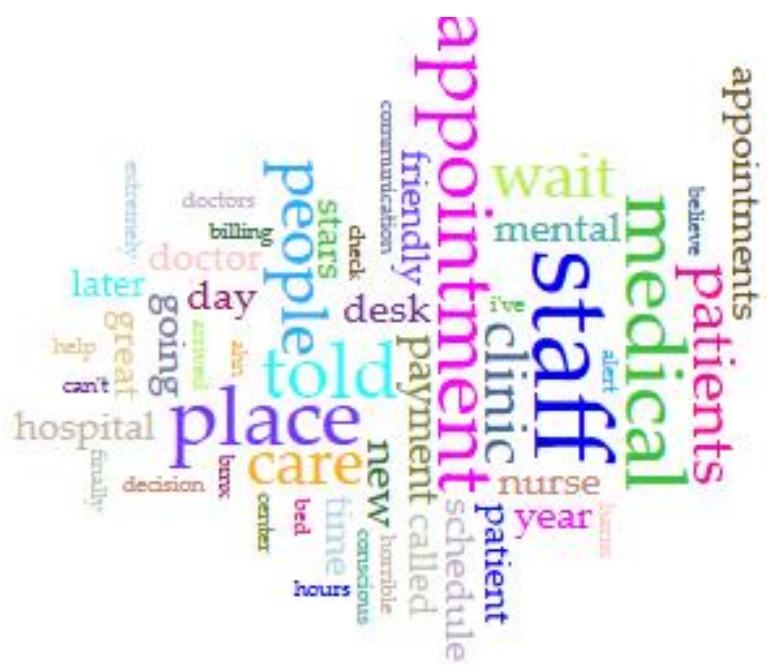

Figure 5: Entire Corpus Word Cloud

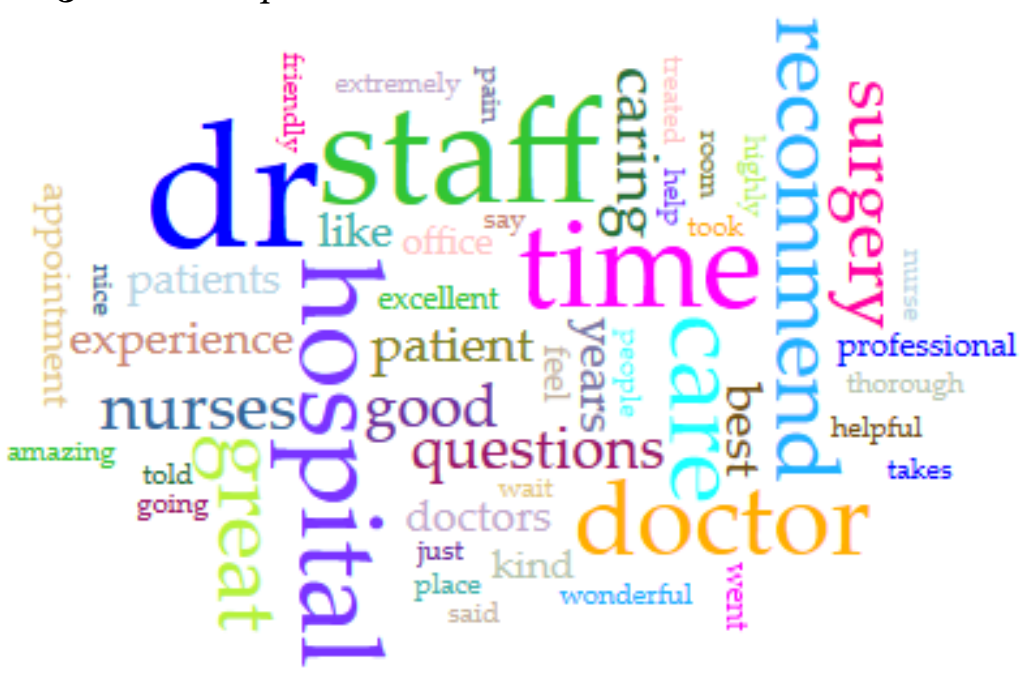


Table 6 contains the top five words by review source, including words such as "staff" for Google and Yelp, "Dr" for Healthgrades, and the entire corpus.

Table 6: Top 5 Words Across Platforms

\begin{tabular}{lllllllc}
\hline Google & & \multicolumn{2}{l}{ Healthgrades } & Yelp & \multicolumn{3}{l}{ Entire Corpus } \\
\hline $\begin{array}{llllll}\text { Top } 5 \\
\text { Words }\end{array}$ & Count & $\begin{array}{l}\text { Top } 5 \\
\text { Words }\end{array}$ & Count & Top 5 Words & Count & $\begin{array}{l}\text { Top 5 } \\
\text { Words }\end{array}$ & Count \\
\hline Staff & 86 & Dr & 175 & Staff & 8 & Dr & 183 \\
Hospital & 85 & Time & 67 & Appointment & 5 & Staff & 146 \\
Care & 57 & Doctor & 62 & Medical & 5 & Time & 99 \\
Nurses & 46 & Staff & 52 & Place & 5 & Hospital & 94 \\
Doctors & 31 & Recommend & 51 & Told & 5 & Doctor & 82 \\
\hline
\end{tabular}

Table 7 contains distinctive language used by review source. Google reviews included distinctive terms like "child," "experience," and "good." Distinctive terms for Healthgrades included "doctor," "takes," "listens," and "explains." Distinctive language in Yelp reviews includes "payments," "transported,” and "thoughts."

The text style for the overall corpus could be described as enunciative and focused on individual perspective and tends to use the term "I." This indicates that these are first-person statements. There were mostly stative verbs used, and time was a common modality across the corpus. Researchers analyzed the corpus by source (Google, Healthgrades, and Yelp). All three sources used an enunciative style utilizing the "I" pronoun indicating a first-person perspective. Time was the top modality across review source, with $22 \%$ of Google's modalities, $25 \%$ of Healthgrades', and $22 \%$ of Yelp's reviews using the time modality.

Table 7: Distinctive Words by Source

\begin{tabular}{|c|c|c|c|c|c|}
\hline \multicolumn{2}{|l|}{ Google } & \multicolumn{2}{|c|}{ Healthgrades } & \multicolumn{2}{|l|}{ Yelp } \\
\hline Distinctive Words & Count & $\begin{array}{l}\text { Distinctive } \\
\text { Words }\end{array}$ & Count & Distinctive Words & Count \\
\hline Child & 15 & Dr. & 175 & Payment & 3 \\
\hline Facility & 10 & Takes & 24 & Western & 2 \\
\hline Baby & 10 & Listens & 23 & Transported & 2 \\
\hline Experience & 26 & Recommend & 51 & Thoughts & 2 \\
\hline Good & 25 & Hip & 16 & Suicidal & 2 \\
\hline
\end{tabular}

Table 8 contains the word pairs, with Google's top word pair being "nurse >doctor" and "doctor $>$ nurse," while Healthgrades top pair was "doctor>year" and "greeting>doctor," indicating the importance of behavior between nurses and doctors as well as between medical staff and patients. Due to the small sample size of written comments, Yelp only had one relevant pair, "communication>delay," which supports the importance of communication with patients seen in Google and Healthgrades comments. 
Table 8: Top Word Relations Pairs by Review Source

\begin{tabular}{cccccc}
\hline Google & \multicolumn{2}{c}{ Healthgrades } & Yelp \\
\hline Word Pair & Pairs & Word Pair & Pairs & Word Pair & Pairs \\
Nurse $>$ Doctor & 10 & Doctor $>$ Year & 8 & Communication $>$ Delay & 2 \\
Doctor $>$ Nurse & 7 & Greeting $>$ Doctor & 7 & \\
Child $>$ Hospital & 7 & Time>Patient & 6 & \\
Hospital $>$ Pennsylvania & 7 & Knee> Replacement & 5 & \\
UPMC $>$ Hospital & 5 & Time>Office & 5 & \\
\hline
\end{tabular}

Figures 6-9 display star diagrams. For the Google corpus, the central term was "hospital," for Healthgrades, the central term was "doctor," and for Yelp's corpus, the central term was "patient." Each central term represents the focus of each site, with Google reviews about the hospitals, Healthgrades reviews primarily about physicians, and Yelp reflecting the views of the patients. Proper names were removed and replaced with the words "person" or "hospital name" to maintain anonymity. The star diagrams were created again for the corpus organized by positive and negative ratings by website.

Note. For Figures 6-9, the numbers found next to the text represent the number of times the words appear in this position in the text.

Figure 6: Google Comments Star Diagram

\begin{tabular}{|c|c|c|c|}
\hline child 7 & & $\cdots \cdots \cdots$ & 7 pennsylvania \\
\hline $\begin{array}{l}\text { Hosptal } \\
\text { Name }\end{array}$ & & $\ldots \ldots \ldots \ldots$ & 3 patient \\
\hline experience 3 & & & 2 floor \\
\hline passavant 2 & & & 2 son \\
\hline shadyside 2 & & & 2 child \\
\hline people 2 & & & 2 area \\
\hline place 2 & ....... & 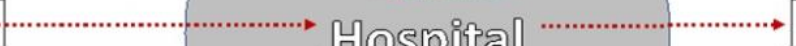 & 2 city \\
\hline one 2 & .......... & , & 2 u_s_a \\
\hline father 2 & & (n) & 1 west_virginia \\
\hline clair 1 & & & 1 california \\
\hline iom 1 & & 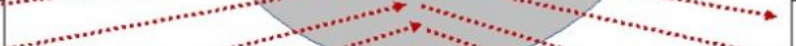 & 1 week \\
\hline donot 1 & & & 1 thing \\
\hline culture 1 & & & 1 guest \\
\hline woman 1 & $\cdots$ & 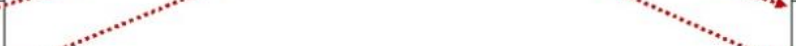 & 1 similarity \\
\hline asset 1 & & & 1 one \\
\hline
\end{tabular}


Islam et al., 2021

Figure 7: Healthgrades Star Diagram

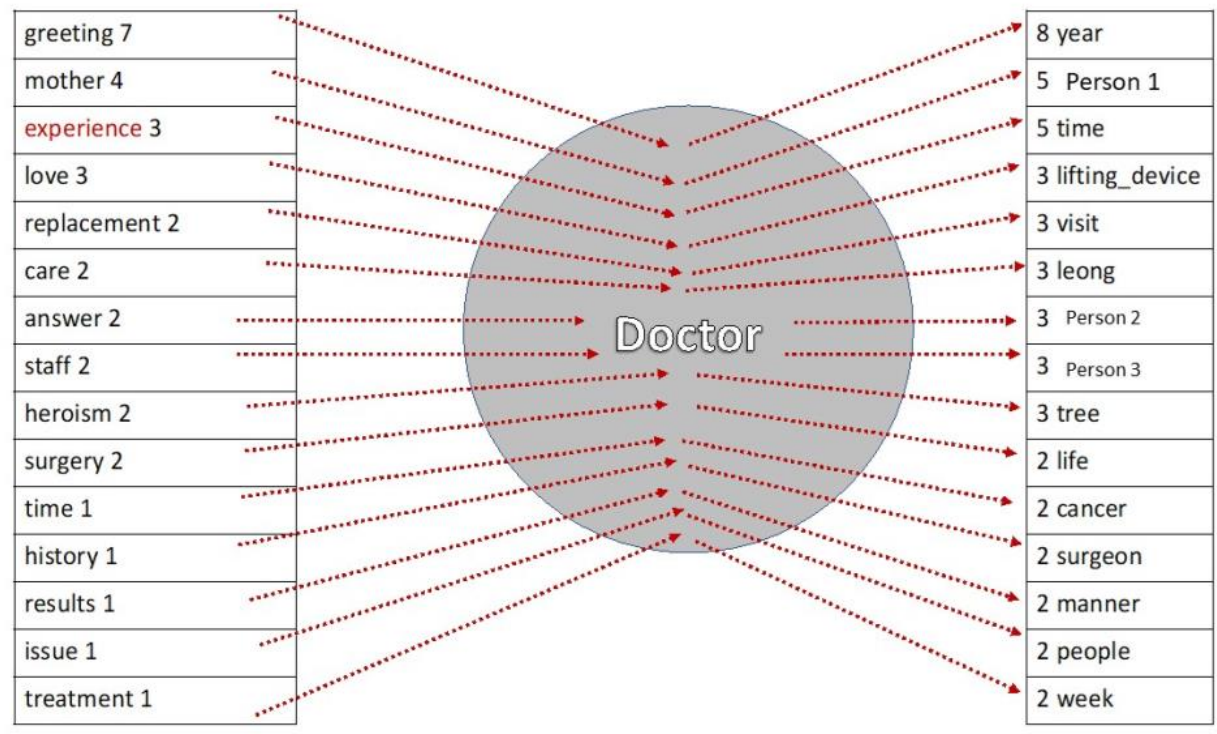

Figure 8: Yelp Star Diagram

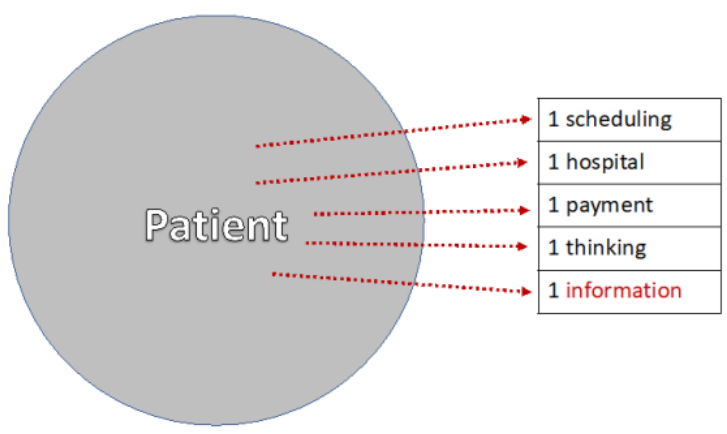


Islam et al., 2021

Figure 9: Entire Corpus Star Diagram

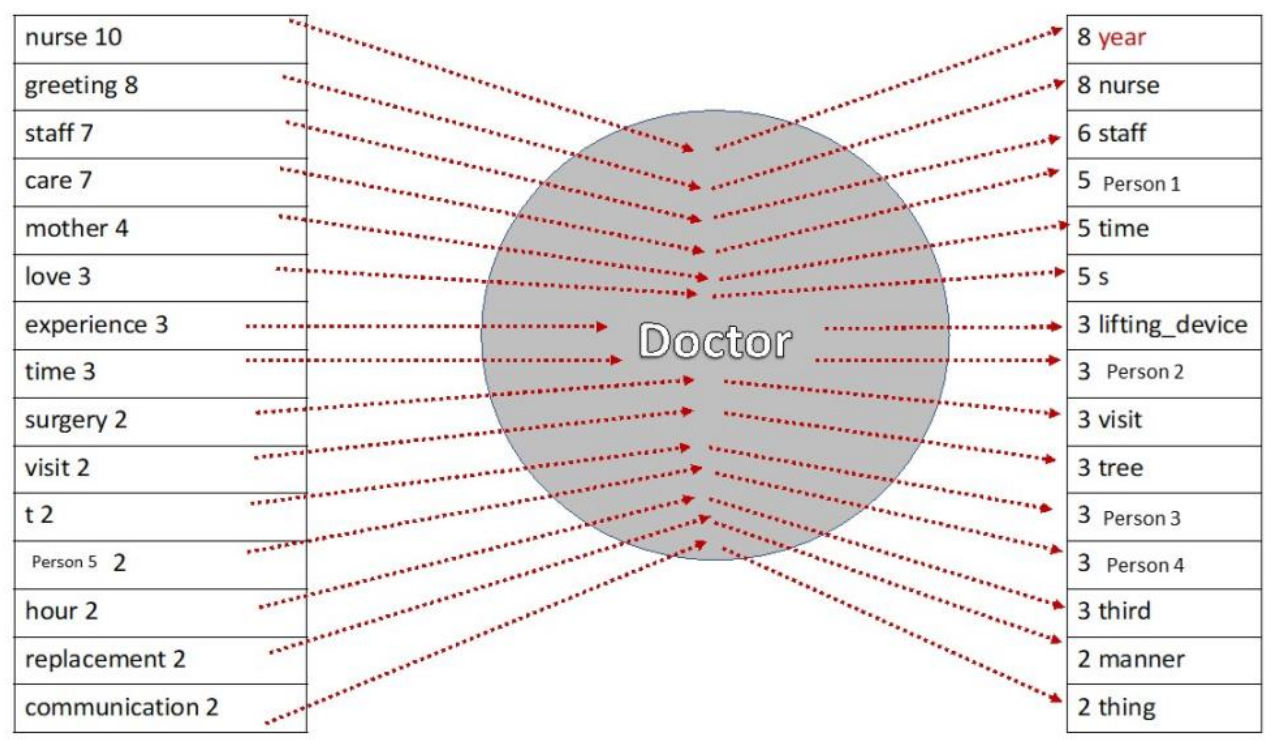

Figures 10-15 indicate star diagrams organized by review source as well as the overall corpus. The central term for Google reviews was the term "hospital." The central term for Healthgrades was "doctor" and for Yelp reviews, "patient." The researchers then constructed star diagrams based on positive and negative reviews and review source. Google positive comments are driven by the term "staff." Yelp positive comments also reflected "staff," while Healthgrades' positive and negative comments were centered around the term "doctor."

Note. For Figures 10-15, the numbers found next to the text represent the number of times the words appear in this position in the text.

Figure 10: Google Negative Comments Star Diagram

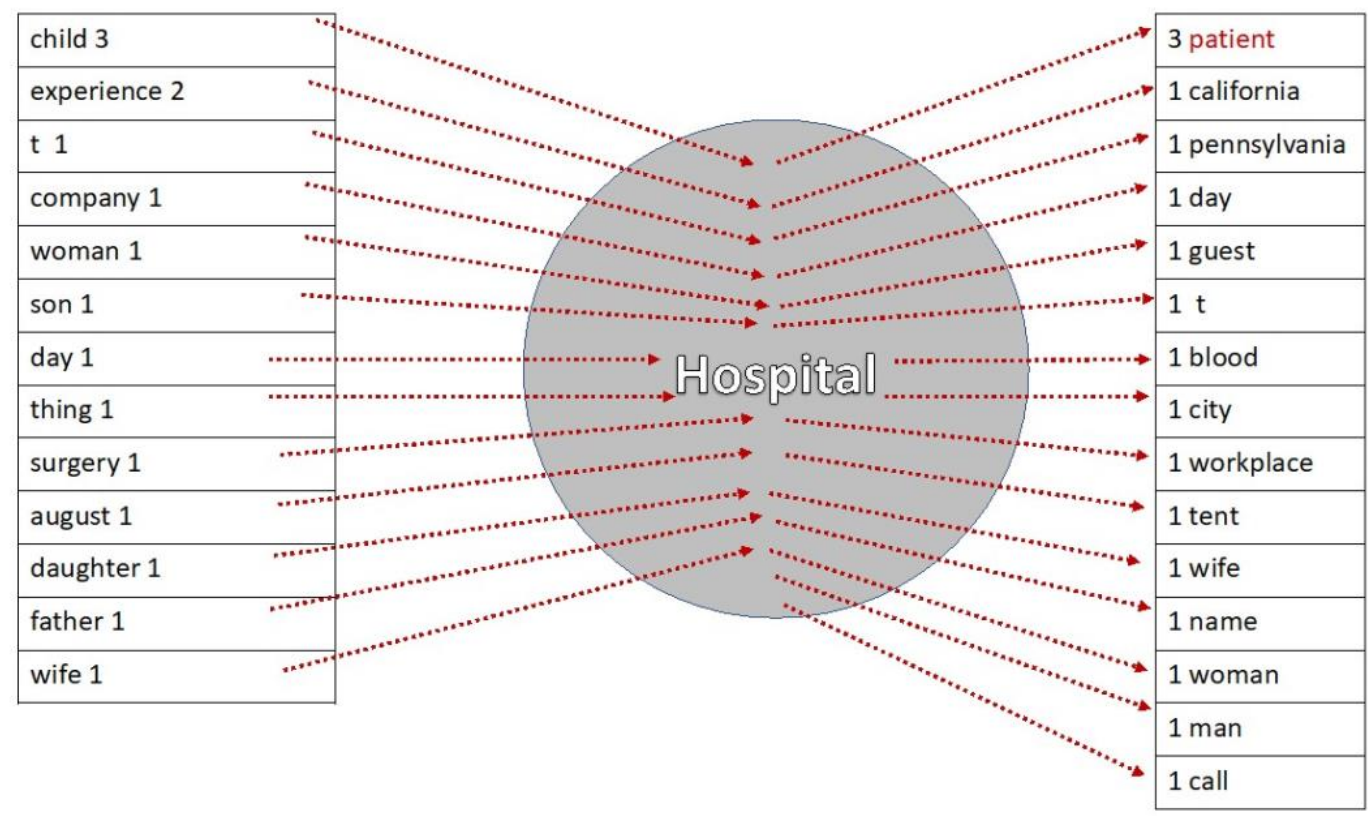


Figure 11: Google Positive Comments Star Diagram

dector 3

\section{Figure 12: Healthgrades Negative Star Diagram}

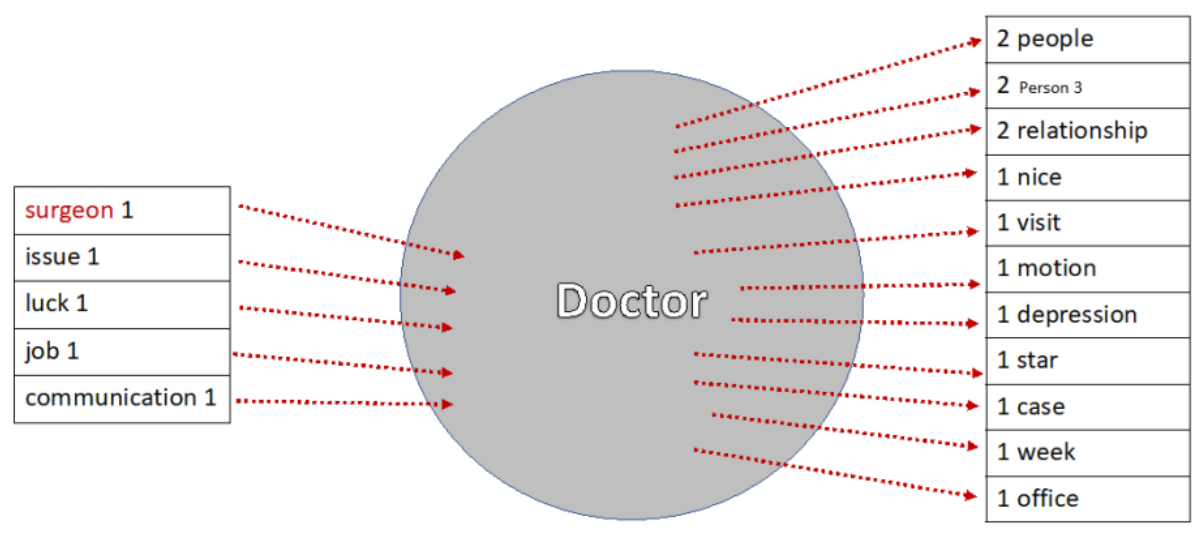


Figure 13: Healthgrades Positive Star Diagram

\begin{tabular}{|c|c|c|c|}
\hline greeting 7 & & *.. & 8 year \\
\hline mother 4 & & $\rightarrow$ & 5 Person 1 \\
\hline love 3 & & 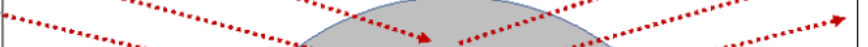 & 5 time \\
\hline experience 3 & & & $4 \mathrm{~s}$ \\
\hline answer 2 & & & 3 Person 2 \\
\hline heroism 2 & & $\Rightarrow$ & 3 Person 3 \\
\hline care 2 & (......... & 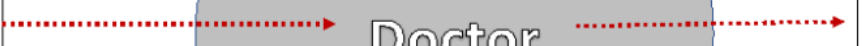 & 3 tree \\
\hline staff 2 & ….... & , n............. & 3 lifting_device \\
\hline replacement 2 & & $\cdots$ & 2 job \\
\hline t 2 & & $\cdots+\cdots+x^{\prime}$ & 2 cancer \\
\hline surgery 2 & & $* \cdots+\cdots$ & 2 surgeon \\
\hline time 1 & & $* *$ & 2 manner \\
\hline history 1 & $\cdots \cdots+$ & & 2 Person 4 \\
\hline linear_unit 1 & & & 2 life \\
\hline manner 1 & $\therefore+$ & & 2 Person 5 \\
\hline
\end{tabular}

Figure 14: Yelp Negative Comments Star Diagram

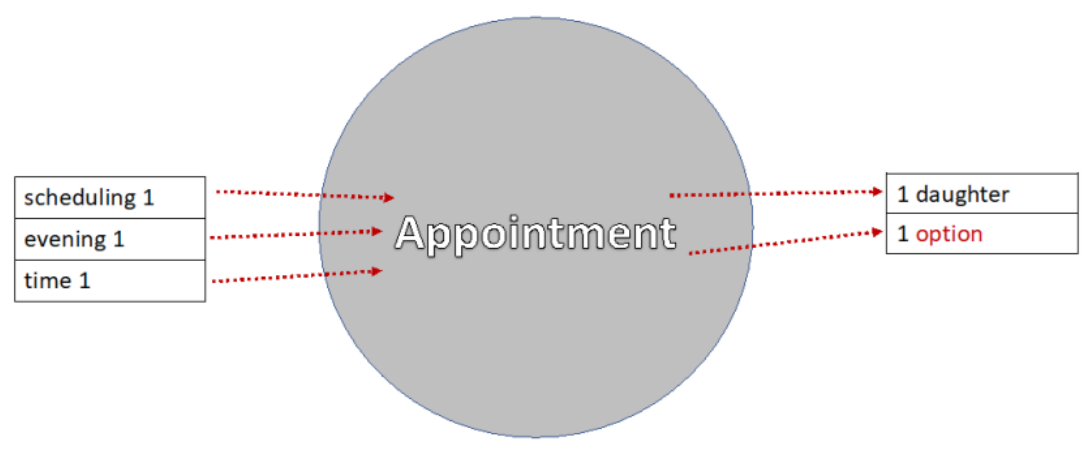


Islam et al., 2021

Figure 15: Yelp Positive Comments Star Diagram

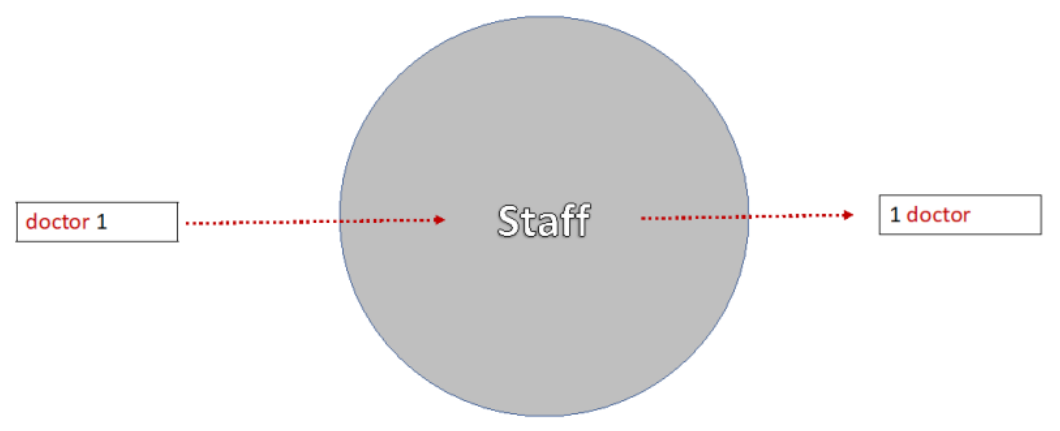

\section{Discussion}

The present research provides some insight into how different platforms may reflect patients' perspectives. The results of this paper indicate that patient comments often reflect the goals of the website itself. Website structure and focus are key factors in determining what the qualitative comments found on the site are focused on. For example, Yelp is a user-generated site focused on patients' individual experiences and thus terms like "appointment" and "doctor" were of key importance. Google comments were pulled around the hospital names and thus the ratings and comments reflected a focus on the hospital itself.

Previous research on open-source comments has not noted the impact of the website focus on the types of comments. Evaluating the instructions and approach of different sites should be a consideration for social media managers that work in a healthcare setting. Depending on what their organizations or practitioners value, they may prioritize comments from different websites and social media accounts. While the tone of the language and the sentiment offered was slightly different, the comments are where true changes can be identified and made. Hospitals should continue to evaluate staff and services through external and internal patient feedback.

The results of the present study also highlight the importance of staff interactions. While previous research has shown the importance of hospital staff in patient experiences, the present results indicate the power of staff to impact social media ratings that may lead to future business. Hospital systems should maintain effective human resource systems and provide rewards to staff around these types of positive interactions. Social media managers and HR professionals should collaborate on identifying those staff behaviors that most drive positive social media comments.

\section{Limitations}

The present study was limited by several factors. First, the time was limited to less than a year. An expanded timeframe, especially one that includes flu season, might result in an increased understanding of patient experiences. A longer timeframe might also allow researchers to map qualitative feedback over time to see if there are seasonal differences in how patients view their hospital experience. The present study was also 
limited by the number of websites used. To generate a more comprehensive comparison between healthoriented websites and more general consumer-oriented sites, additional website comments must be added. Finally, the single location also limited the results. Additional cities and locations may provide researchers with greater understanding of patient experiences across states and even countries.

\section{Future Research}

The present study provided some interesting initial results but serves as an exploratory analysis of social media comments. Future research should attempt to develop a predictive model of textual analysis and social media comments with bottom-line factors such as revenue, returning patients, and referrals. The focus of this study was also on one city. Future research should try to expand this approach to other cities and countries to evaluate cross-cultural effects on social media comments. Identifying key drivers of social media comments in other countries may illuminate expectations of service.

\section{Relevance to Clinical Practice}

In terms of clinical practice, patient feedback from different sources is important in that it may alter the postoperative instructions or care given to patients that have undergone similar procedures. At times, patients do not follow up with post-operative visits, so in these cases, user feedback on the different websites can help clinicians learn what post-operative instructions worked better than others. Interestingly, similar studies of patient feedback based on the care they received either reported no effects, small non-statistically significant improvements, or few statistically significant changes in clinical practice (Kumah et al., 2018). It is important to note that the instructions on the website to write a review may also impact the ratings and comments a clinician may receive.

Clinical practice has already been impacted by social media from a business perspective (Eckler et al., 2010). As noted by Hors-Frail et al. (2016), social media has both a positive and negative side. The present paper highlights the importance of choosing which website to follow based on the purpose of the site itself. While these sites may provide some insights, they should not be used to drive clinical practice but rather customer service initiatives for a hospital's patients.

\section{Conclusions}

The present study provides some clear insights into online social media comments from health-related websites. Medical professionals in clinical practice utilized social media in their decision-making processes (Hawn, 2009). The findings of this study highlight the importance of understanding the source of these reviews. Users tend to adhere to the guidelines provided by the platform or website through which they are providing feedback. Healthcare practitioners should identify the most relevant website and social media pages that drive their practices' business and provide the most clinical insight. Additionally, this study's findings highlight the importance of hospital staff in the patient experience. The work of healthcare practitioners is the most important driver in patients' healthcare experience. Clinical practitioners should use different social media and websites to evaluate patient perceptions of their services. 


\section{References}

Abirami, A. M., \& Askarunisa, A. (2017). Sentiment analysis model to emphasize the impact of online reviews in healthcare industry. Online Information Review, 41(4), 471-486. https://doi.org/10.1108/OIR-082015-0289

Abualigah, L., Alfar, H. E., Shehab, M., \& Hussein, A. M. A. (2020). Sentiment analysis in healthcare: A brief review. In Recent advances in NLP: The case of Arabic language (pp. 129-141). Springer, Cham.

Al-Busaidi, Z. Q. (2008). Qualitative research and its uses in health care. Sultan Qaboos University Medical Journal, 8(1), 11.

Antheunis, M. L., Tates, K., \& Nieboer, T. E. (2013). Patients' and health professionals' use of social media in health care: Motives, barriers and expectations. Patient Education and Counseling, 92(3), 426-431. https://doi.org/10.1016/j.pec.2013.06.020

Apenteng, B. A., Ekpo, I. B., Mutiso, F. M., Akowuah, E. A., \& Opoku, S. T. (2020). Examining the relationship between social media engagement and hospital revenue. Health Marketing Quarterly, 37(1), 10-21. https://doi.org/10.1080/07359683.2020.1713575

Atinga, R. A., Abekah-Nkrumah, G., \& Domfeh, K. A. (2011). Managing healthcare quality in Ghana: A necessity of patient satisfaction. International Journal of Health Care Quality Assurance. https://doi.org/10.1108/09526861111160580

Auriemmo, A., Islam, S., Auriemmo, J., \& Mazzola, J. (2018). Employer and customer branding: An essential linkage leveraged through social media. Journal of Management and Innovation (4)1. https://jmi.mercy.edu/index.php/JMI/article/view/56

Bakhsh, W., \& Mesfin, A. (2014). Online ratings of orthopedic surgeons: Analysis of 2185 reviews. American Journal of Orthopedics, 43(8), 359-63.

Black, E., Thompson, L., Saliba, H., Dawson, K., \& Black, N. P. (2009). An analysis of healthcare providers' online ratings. Journal of Innovation in Health Informatics, 17(4), 249-253. http://dx.doi.org/10.14236/jhi.v17i4.744

Bradbury-Jones, C., Taylor, J., Kroll, T., \& Duncan, F. (2014). Domestic abuse awareness and recognition among primary healthcare professionals and abused women: A qualitative investigation. Journal of Clinical Nursing, 23(21-22), 3057-3068. https://doi.org/10.1111/jocn.12534

Boyd, R. (2013). RIOT Scan: Recursive inspection of text. https://www.ryanboyd.io/software/riot/

Bradley, J. (2005). What you (fore) see is what you get: Thinking about usage paradigms for computer assisted text analysis. Text Technology, 14(2), 1.

Chan, K. L., \& Chen, M. (2019). Effects of social media and mobile health apps on pregnancy care: Meta analysis. JMIR mHealth and uHealth, 7(1), e11836. https://doi.org/10.2196/11836

Chenail, R. J. (2011). How to conduct clinical qualitative research on the patient's experience. Qualitative Report, 16(4), 1173-1190. https://nsuworks.nova.edu/tqr/vol16/iss4/14

Chetta, M. H., Islam, S., Kozikowski, A., Cassel, D., Bandara, B., \& Sanchez, D. C. (2017). A qualitative model for customer behavioral decisions and satisfaction in the hospitality industry. Journal of Management and Innovation, 3(2). https://touroscholar.touro.edu/dbs_pubs/45

Cohen, D. J., \& Crabtree, B. F. (2008). Evaluative criteria for qualitative research in health care: Controversies and recommendations. The Annals of Family Medicine, 6(4), 331-339. https://doi.org/10.1370/afm.818 
Cordoș, A. A., Bolboacă, S. D., \& Drugan, C. (2017). Social media usage for patients and healthcare consumers: A literature review. Publications, 5(2), 9. https://doi.org/10.3390/publications5020009

Daku, M., Soroka, S., and Young, L. 2015. Lexicoder, Version 3.0. www.lexicoder.com

DeVries, P. D. (2012). Electronic social media in the healthcare industry. International Journal of Electronic Finance, 6(1), 49-61. https://doi.org/10.1504/IJEF.2012.046593

Donnally C. J., III, Li, D. J., Maguire J. A., Jr., Roth, E. S., Barker, G. P., McCormick, J. R., Rush, A. J., \& Lebwohl, N. H. (2018). How social media, training, and demographics influence online reviews across three leading review websites for spine surgeons. The Spine Journal, 18(11), 2081-2090. https://doi.org/10.1016/j.spinee.2018.04.023

Duriau, V. J., Reger, R. K., \& Pfarrer, M. D. (2007). A content analysis of the content analysis literature in organization studies: Research themes, data sources, and methodological refinements. Organizational Research Methods, 1O(1), 5-34. https://doi.org/10.1177/1094428106289252

Eckler, P., Worsowicz, G., \& Rayburn, J. (2010). Social media and healthcare: An overview. PM\&R, 2(11), 1046-1050. https://doi.org/10.1016/j.pmrj.2010.09.005

Fossey, E., Harvey, C., McDermott, F., \& Davidson, L. (2002). Understanding and evaluating qualitative research. Australian \& New Zealand Journal of Psychiatry, 36(6), 717-732. https://doi.org/10.1046/j.1440-1614.2002.01100.x

Georgiou, D., MacFarlane, A., \& Russell-Rose, T. (2015, July). Extracting sentiment from healthcare survey data. In An evaluation of sentiment analysis tools, Science and Information Conference, London, United Kingdom. https://doi.org/10.1109/SAI.2015.7237168

Grajales F. J., III, Sheps, S., Ho, K., Novak-Lauscher, H., \& Eysenbach, G. (2014). Social media: A review and tutorial of applications in medicine and health care. Journal of Medical Internet Research, 16(2), e13. https://doi.org/10.2196/jmir.2912

Gravili, G. (2013, September). Opportunities and risks of the use of social media in healthcare organizations In P. Lech (Ed.), Proceedings of the 7th European Conference on Information Management and Evaluation, University of Gdańsk, Poland. https://issuu.com/acpil/docs/ecime 2013_proceedings

Greaves, F., \& Millett, C. (2012). Consistently increasing numbers of online ratings of healthcare in England. Journal of Medical Internet Research, 14(3), e94. https://doi.org/10.2196/jmir.2157

Greaves, F., Ramirez-Cano, D., Millett, C., Darzi, A., \& Donaldson, L. (2013). Use of sentiment analysis for capturing patient experience from free-text comments posted online. Journal of Medical Internet Research, 15(11), e239. https://www.jmir.org/2013/11/e239/

Griffis, H. M., Kilaru, A. S., Werner, R. M., Asch, D. A., Hershey, J. C., Hill, S., Ha, Y. P., Sellers, A., Mahoney, K., \& Merchant, R. M. (2014). Use of social media across US hospitals: Descriptive analysis of adoption and utilization. Journal of Medical Internet Research, 16(11), e264. https://doi.org/10.2196/jmir.3758

Hamm, M. P., Chisholm, A., Shulhan, J., Milne, A., Scott, S. D., Given, L. M., \& Hartling, L. (2013). Social media use among patients and caregivers: A scoping review. BMJ open, 3(5). https://doi.org/10.1136/bmjopen-2013-002819

Hawn, C. (2009). Take two aspirin and tweet me in the morning: How Twitter, Facebook, and other social media are reshaping health care. Health Affairs, 28(2), 361-368. https://doi.org/10.1377/hlthaff.28.2.361

Hicks, A., Comp, S., Horovitz, J., Hovarter, M., Miki, M., \& Bevan, J. L. (2012). Why people use Yelp.com: An exploration of uses and gratifications. Computers in Human Behavior, 28(6), 2274-2279. 
Hilliard, C. (2012). Social media for healthcare: A content analysis of MD Anderson's Facebook presence and its contribution to cancer support systems. The Elon Journal of Undergraduate Research in Communications, 3(1), 23-32. https://www.elon.edu/u/academics/communications/journal/wpcontent/uploads/sites/153/2017/06/03HilliardEJSpring12.pdf

Hors-Fraile, S., Atique, S., Mayer, M. A., Denecke, K., Merolli, M., \& Househ, M. (2016). The unintended consequences of social media in healthcare: New problems and new solutions. Yearbook of Medical Informatics, (1), 47. https://doi.org/10.15265/IY-2016-009

Househ, M. (2013, February). The use of social media in healthcare: Organizational, clinical, and patient perspectives. In K. L. Courtney, O. Shabestari, A. Kuo (Eds.), Enabling health and healthcare through ICT: Available, tailored and closer [Conference proceedings], 183, 244. Information Technology and Communication in Health 2013 Conference, Victoria, BC, Canada. https://doi.org/10.3233/978-161499-203-5-244

Islam, S., Chetta, M., Kozikowski, A., \& Misner, S. (2016). Speaking of urgent care centers: Language matters. Journal of Management and Innovation, 2(1), 1-18. http://jmi.mercy.edu/index.php/JMI/article/view/14 https://doi.org/10.18059/jmi.v2i1.14

Kordzadeh, N. (2018, January). Physician ratings published on healthcare organizations' websites: Are they biased? In Proceedings of the $51^{\text {st }}$ Hawaii International Conference on System Sciences, Waikoloa Village, Hawaii

Kumah, E., Ankomah S. E., \& Kesse, F.O. (2018). The impact of patient feedback on clinical practice. British Journal of Hospital Medicine, 79(12), 700-703. https://doi.org/10.12968/hmed.2018.79.12.700.

Lagu, T., Metayer, K., Moran, M., Ortiz, L., Priya, A., Goff, S. L., \& Lindenauer, P. K. (2017). Website characteristics and physician reviews on commercial physician-rating websites. Jama, 317(7), 766768. https://doi.org/10.1001/jama.2016.18553

Laranjo, L., Arguel, A., Neves, A. L., Gallagher, A. M., Kaplan, R., Mortimer, N., Mendes, G. A., \& Lau, A. Y. (2015). The influence of social networking sites on health behavior change: A systematic review and meta-analysis. Journal of the American Medical Informatics Association, 22(1), 243-256. https://doi.org/10.1136/amiajnl-2014-002841

McCaughey, D., Baumgardner, C., Gaudes, A., LaRochelle, D., Wu, K. J., \& Raichura, T. (2014). Best practices in social media: Utilizing a value matrix to assess social media's impact on health care. Social Science Computer Review, 32(5), 575-589. https://doi.org/10.1177/0894439314525332

McLennan, S. (2019). Quantitative ratings and narrative comments on Swiss physician rating websites: frequency analysis. Journal of Medical Internet Research, 21(7), e13816. https://doi.org/10.2196/13816

Miyata, H., \& Kai, I. (2009). Reconsidering evaluation criteria for scientific adequacy in health care research: An integrative framework of quantitative and qualitative criteria. International Journal of Qualitative Methods, 8(1), 64-75. https://doi.org/10.1177/160940690900800106

Morahan-Martin, J. M. (2004). How internet users find, evaluate, and use online health information: A crosscultural review. CyberPsychology \& Behavior, 7(5), 497-510. https://doi.org/10.1089/cpb.2004.7.497

Morris, R. (1994). Computerized content analysis in management research: A demonstration of advantages \& limitations. Journal of management, 20(4), 903-931. https://doi.org/10.1016/01492063(94)90035-3

Nwachukwu, B. U., Adjei, J., Trehan, S. K., Chang, B., Amoo-Achampong, K., Nguyen, J. T., Taylor, S. A., McCormick, F., \& Ranawat, A. S. (2016). Rating a sports medicine surgeon's “quality" in the modern 
era: An analysis of popular physician online rating websites. HSS Journal $(12(3), 272-277$. https://doi.org/10.1007/s11420-016-9520-x

Popay, J., \& Williams, G. (1998). Qualitative research and evidence-based healthcare. Journal of the Royal Society of Medicine, 91(35_suppl), 32-37.

Pope, C., Van Royen, P., \& Baker, R. (2002). Qualitative methods in research on healthcare quality. BMJ Quality \& Safety, 11(2), 148-152. https://doi.org/10.1136/qhc.11.2.148

Pope, C., Ziebland, S., \& Mays, N. (2000). Qualitative research in health care. BMJ (320) 114-116. https://doi.org/10.1136/bmj.320.7227.114

Ranney M. L., \& Genes, N. (2016). Social media and healthcare quality improvement: A nascent field. $B M J$ Quality \& Safety, 25, 389-391.

Roth, D. N. P., \& Whitehead, D. (2019). Impact of a nurse manager peer mentorship program on job satisfaction and intent to stay. Journal of Excellence in Nursing and Healthcare Practice, 1(1), 4-14. https://doi.org/10.5590/JENHP.2019.1.1.02

Sabel, M. S., \& Dal Cin, S. (2016). Trends in media reports of celebrities' breast cancer treatment decisions. Annals of Surgical Oncology, 23(9), 2795-2801. https://doi.org/10.1245/s10434-016-5202-7

Sarasohn-Kahn, J. (2008). The wisdom of patients: Health care meets online social media. https://www.researchgate.net/profile/Jane Sarasohn-

Kahn/publication/242101734 The Wisdom_of_Patients_Health_Care_Meets_Online_Social_Med ia/links/59e5f35dof7egboe1ab25bc5/The-Wisdom-of-Patients-Health-Care-Meets-Online-SocialMedia.pdf

Schultz, A. S., Finegan, B., Nykiforuk, C. I., \& Kvern, M. A. (2011). A qualitative investigation of smoke-free policies on hospital property. CMAJ, 183(18), E1334-E1344. https://doi.org/10.1503/cmaj.110235

Smailhodzic, E., Boonstra, A., \& Langley, D. (2016). Towards new social media logic in healthcare and its interplay with clinical logic. https://pdfs.semanticscholar.org/45a6/32dod5e6d223c22bc8531d634137d3bo155a.pdf

Smith, S. M., O’Leary, M., Bury, G., Shannon, W., Tynan, A., Staines, A., \& Thompson, C. (2003). A qualitative investigation of the views and health beliefs of patients with Type 2 diabetes following the introduction of a diabetes shared care service. Diabetic Medicine, 2O(10), 853-857.

Soroka, S., Young, L., \& Balmas, M. (2015). Bad news or mad news? Sentiment scoring of negativity, fear, and anger in news content. The ANNALS of the American Academy of Political and Social Science, 659(1), 108-121. https://doi.org/10.1177/0002716215569217

Terry, M. (2009). Twittering healthcare: Social media and medicine. Telemedicine and e-Health, 15(6), 507510. https://doi.org/10.1089/tmj.2009.9955

Thelwall, M. (2008). Quantitative comparisons of search engine results. Journal of the American Society for Information Science and Technology, 59(11), 1702-1710. https://doi.org/10.1002/asi.20834

Tian, Y., \& Stewart, C. M. (2005). Framing the SARS crisis: A computer-assisted text analysis of CNN and BBC online news reports of SARS. Asian Journal of Communication, 15(3), 289-301.

Todres, L., Galvin, K. T., \& Holloway, I. (2009). The humanization of healthcare: A value framework for qualitative research. International Journal of Qualitative Studies on Health and Well-being, 4(2), 68-77. https://doi.org/10.1080/17482620802646204

Ventola, C. L. (2014). Social media and health care professionals: Benefits, risks, and best practices. Pharmacy and Therapeutics, 39(7), 491. 
Williams G., Hamm M. P., Shulhan, J., Vandermeer, B., Hartling L. (2104). Social media interventions for diet and exercise behaviours: A systematic review and meta-analysis of randomised controlled trials. BMJ Open 4(2):e003926. https:doi.org/10.1136/bmjopen-2013-003926

Young, L., \& Soroka, S. (2012). Affective news: The automated coding of sentiment in political texts. Political Communication, 29(2), 205-231. https://doi.org/10.1080/10584609.2012.671234

\footnotetext{
O JENHP

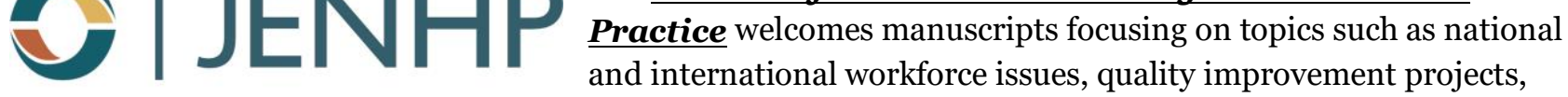
evidence-based practice initiatives, nursing research studies, interprofessional practice, educational issues, telehealth, improvements in technology, and the impact of social change in society.
} 